Pesq. Vet. Bras. 30(6):503-509, junho 2010

\title{
Evidência molecular de Brucella sp. em Ozotoceros bezoarticus (veado campeiro) do Pantanal Sul-Mato- Grossense $^{1}$
}

\author{
Carina Elisei², Aiesca Pellegrin ${ }^{3}$, Walfrido M. Tomas ${ }^{3}$, Cleber O. Soares², \\ Flábio R. Araújo ${ }^{2}$, Maribel E. Funes-Huacca² e Grácia M.S. Rosinha ${ }^{2}$
}

\begin{abstract}
Elisei C., Pellegrin A., Tomas W.M., Soares C.O., Araújo F.R., FunesHuacca M.E. \& Rosinha G.M.S. 2010. [Molecular evidence of Brucella sp. in deer (Ozotoceros bezoarticus) of the southern Pantanal.] Evidência molecular de Brucella sp. em Cervídeos (Ozotoceros bezoarticus) do Pantanal Sul-Mato-Grossense. Pesquisa Veterinária Brasileira 30(6):503-509. Sanidade Animal, Embrapa Gado de Corte, BR 262 Km 4, Caixa Postal 154, Campo Grande, MS 79002-970, Brazil. E-mail: rosinha@cnpgc.embrapa.br

The presence of Brucella spp. in wild animals can influence their reproduction rate and may be a source of infection for domestic animals and humans. The objective of this study was to identify the presence of Brucella spp. in 44 blood samples from the deer Ozotoceros bezoarticus in the southern Pantanal of Sul-Mato-Grossense, using the PCR technique. It was seen that $20.4 \%(9 / 44)$ of the samples were positive. The consensus sequence was obtained by sequencing these samples, which then showed $514 \mathrm{pb}$ and $95 \%$ of identity with gene virB5 of $B$. abortus (best hits accession $\mathrm{nr}$ AF226278, e-value 0.0 ). The phylogenetic analysis of the sample isolated from deer revealed the Brucella to be very close to $B$. suis. The high percentage of positive samples suggests that brucellosis may be a concern in deer within the studied area, and that these animals may poses a risk for other domestic and wild ones.
\end{abstract}

INDEX TERMS: Brucellosis, deer, PCR, Pantanal.

RESUMO.- A presença de Brucella spp. entre animais silvestres pode influenciar a taxa de reprodução destes hospedeiros, além de atuarem como fonte de infecção natural para os animais domésticos e humanos. O objetivo deste estudo foi identificar a presença de Brucella spp. em 44 amostras de sangue de veado campeiro (Ozotoceros bezoarticus) do Pantanal do Sul-Mato-Grossense, utilizando a técnica de PCR. Observou-se que 20,4\% (9/44) das amostras foram positivas. A sequência consenso de nucleotídeo obtida no sequenciamento do isolado de veado campeiro apresentou $514 \mathrm{pb}$ e $95 \%$ de identidade com virB5 de B. abortus (best hits acesso nr AF226278, e-value 0.0), já na análise filogenética a amostra de Brucella isolada de veado campeiro apresentou-se muito próximo de $B$. suis. A alta porcentagem de amostras positivas sugere que a

\footnotetext{
${ }^{1}$ Recebido em 1 de outubro de 2009.

Aceito para publicação em 7 de junho de 2010.

2 Embrapa Gado de Corte, BR 262 Km 4, Caixa Postal 154, Campo Grande, MS 79002-970, Brasil. E-mail: rosinha@ cnpgc.embrapa.br

${ }^{3}$ Embrapa Pantanal, Rua 21 de Setembro 1880, Corumbá, MS 79320900, Brasil.
}

brucelose pode ser um problema entre os veados campeiros na área estudada e que estes animais podem representar riscos para outros animais domésticos e silvestres.

TERMOS DE INDEXAÇÃO: Brucelose, cervídeos, PCR, Pantanal.

\section{INTRODUÇÃO}

Ozotoceros bezoarticus Linnaeus 1758, (veado campeiro) pertence à Ordem Artiodactyla, família Cervidae; originalmente esta espécie apresentava uma ampla distribuição geográfica na América do Sul, abrangendo todos os ambientes abertos, como savanas, campos e os pampas. Atualmente esta espécie está restrita a populações isoladas na Argentina, Uruguai, Bolívia, Paraguai e Brasil (Tomás et al. 2001), devido à expansão da agricultura e urbanização (Gonzáles et al. 2010). No Pantanal Sul-Mato-Grossense as populações de $O$. bezoarticus estão localizadas principalmente na região central do Pantanal, na região da Nhecolândia e Paiaguás, com maior número de animais em áreas de campos e vazantes (Mourão et al. 2000, Tomás et 
al. 2001). Esta região constitui um sistema ecológico, onde coabitam diversas espécies de cervídeos, de taiassuídeos, bovídeos e outros animais domésticos e silvestres (Nascimento et al. 2000).

As espécies de bactérias do gênero Brucella são Gramnegativas, intracelulares facultativa, responsável por uma das doenças infecciosas de maior impacto econômico na medicina veterinária, devido aos prejuízos causados em consequência aos distúrbios reprodutivos que ocorrem nos animais domésticos e silvestres. A brucelose é ainda uma das mais importantes e disseminadas zoonoses no mundo, sendo responsável por problemas sanitários e econômicos, particularmente nos trópicos e em países com pouco investimento nas áreas de produção de leite e carne, onde a sua incidência é alta (Poester et al. 2002). Trata-se de uma enfermidade caracterizada por ocasionar infecções nas articulações, epidídimo e abortos que podem ocorrem durante as primeiras gestações, permanecendo uma infecção crônica.

Esta doença é similar em cervídeos (Thorne et al. 1997, Conner et al 2008, Rhyan et al. 2009), porém pouco se sabe sobre este agente infectando os animais silvestres no Pantanal Sul-Mato-Grossense. A primeira forma significativa de transmissão para os ruminantes é a ingestão de tecido fetal e secreção, que contaminam as pastagens, eliminados durante o aborto ou parto (Rhyan et al. 2009, Olsen \& Tatum 2010).

A infecção por Brucella spp. em animais silvestres vem sendo relatada mundialmente. Pesquisas nas Américas do Norte e do Sul e em outros países têm detectado espécies de Brucella em animais silvestres, sendo que a maioria destes estudos é realizada por meio do diagnóstico sorológico ou por isolamento e cultura (Quadro 1).

A presença deste patógeno entre os animais silvestres pode influenciar a taxa de reprodução destes hospedeiros, além de atuarem como fonte de infecção natural para os animais domésticos e humanos (Mathias et al. 1999).

No Brasil são raros estudos epidemiológicos utilizando técnicas sorológicas e a reação em cadeia da polimerase (PCR) envolvendo animais silvestres. O objetivo deste estudo foi identificar a presença de Brucella sp. em cervídeos O. bezoarticus do Pantanal de Mato Grosso do Sul utilizando a técnica de PCR.

Quadro 1. Pesquisa de anticorpos anti-Brucella abortus compilado de vários autores

\begin{tabular}{|c|c|c|c|c|}
\hline Hospedeiros & $\begin{array}{l}\text { Número } \\
\text { amostral }\end{array}$ & Soropositivo & Local & Autor \\
\hline $\begin{array}{l}\text { Cervídeos } \\
\text { (Odocoileus hemionus) } \\
\text { (Cervus canadensis) }\end{array}$ & 113 & 46 & $\begin{array}{l}\text { Utah } \\
\text { (EUA) }\end{array}$ & $\begin{array}{l}\text { Merrell \& Wright } \\
\qquad(1978)\end{array}$ \\
\hline $\begin{array}{l}\text { Cervídeos } \\
\text { (Odocoileus virginianus) }\end{array}$ & 37 & Ausente & $\begin{array}{l}\text { Texas } \\
\text { (EUA) }\end{array}$ & $\begin{array}{l}\text { Boeer et al. } \\
\text { (1980) }\end{array}$ \\
\hline $\begin{array}{l}\text { Cervídeos } \\
\text { (Odocoileus virginianus) }\end{array}$ & 713 & 1 & $\begin{array}{l}\text { Missouri } \\
\text { (EUA) }\end{array}$ & $\begin{array}{l}\text { Jones et al. } \\
\text { (1983) }\end{array}$ \\
\hline $\begin{array}{l}\text { Cervídeos } \\
\text { (Odocoileus virginianus) }\end{array}$ & 628 & Ausente & $\begin{array}{l}\text { Minnesota } \\
\quad(E \cup A)\end{array}$ & $\begin{array}{l}\text { Ingebrigtsen et al. } \\
\text { (1986) }\end{array}$ \\
\hline $\begin{array}{l}\text { Cervídeos } \\
\text { (Darna dama) } \\
\text { (Odocolleus virginianus) }\end{array}$ & 10 & Ausente & $\begin{array}{l}\text { Kentucky } \\
\text { (EUA) }\end{array}$ & $\begin{array}{l}\text { Davidson et al. } \\
\text { (1985) }\end{array}$ \\
\hline $\begin{array}{l}\text { Cervídeos } \\
\text { (Odocoileus virginianus) }\end{array}$ & 5 & Ausente & México & $\begin{array}{l}\text { Aguirre et al. } \\
\quad(1992)\end{array}$ \\
\hline $\begin{array}{l}\text { Cervídeos } \\
\text { (Odocoileus hemioncus californicus) }\end{array}$ & 355 & 1 & $\begin{array}{l}\text { Califórnia } \\
\text { (EUA) }\end{array}$ & $\begin{array}{l}\text { Drew et al. } \\
\text { (1992) }\end{array}$ \\
\hline $\begin{array}{l}\text { Cervídeos } \\
\text { (Odocoileus hemioncus columbianus) }\end{array}$ & 1.613 & 1 & $\begin{array}{l}\text { Califórnia } \\
\text { (EUA) }\end{array}$ & $\begin{array}{l}\text { Drew et al. } \\
\quad(1992)\end{array}$ \\
\hline Alce(Alces alces) & 208 & Ausente & $\begin{array}{l}\text { Quebec } \\
\text { (Canadá) }\end{array}$ & $\begin{array}{c}\text { Bourque \& Higgins } \\
(1984)\end{array}$ \\
\hline $\begin{array}{l}\text { Capivara } \\
\text { (Hydrochaeris hydrochaeris) }\end{array}$ & 201 & 8 & Venezuela & $\begin{array}{l}\text { Lord \& Flores } \\
\qquad(1983)\end{array}$ \\
\hline $\begin{array}{l}\text { Cervídeos } \\
\text { (Ozotoceros bezoarticus) }\end{array}$ & 17 & Ausente & $\begin{array}{l}\text { Mato Grosso do Sul } \\
\text { Pantanal(Brasil) }\end{array}$ & $\begin{array}{l}\text { Mathias et al. } \\
\text { (1999) }\end{array}$ \\
\hline $\begin{array}{l}\text { Cervídeos } \\
\text { (Ozotoceros bezoarticus) }\end{array}$ & 24 & Ausente & $\begin{array}{l}\text { Goiás } \\
\text { (Brasil) }\end{array}$ & $\begin{array}{l}\text { Mathias et al. } \\
\text { (1999) }\end{array}$ \\
\hline $\begin{array}{l}\text { Cervídeos } \\
\text { (Ozotoceros bezoarticus celer) }\end{array}$ & 14 & Ausente & Argentina & $\begin{array}{l}\text { Uhart et al. } \\
\text { (2003) }\end{array}$ \\
\hline $\begin{array}{l}\text { Cervídeos (Cervus elaphus) } \\
\text { e Bisão (Bison bison) }\end{array}$ & 366 & 117 & $\begin{array}{l}\text { Idaho } \\
\text { (EUA) }\end{array}$ & $\begin{array}{l}\text { Etter \& Drew } \\
\quad(2006)\end{array}$ \\
\hline $\begin{array}{l}\text { Cervídeos } \\
\text { (Mazama gouazoubira) }\end{array}$ & 15 & Ausente & $\begin{array}{l}\text { Gran Chaco } \\
\text { (Bolivia) }\end{array}$ & $\begin{array}{c}\text { Deem et al. } \\
(2004)\end{array}$ \\
\hline Bisão (Bison bison) & 145 & 27 & $\begin{array}{l}\text { Idaho } \\
\text { (EUA) }\end{array}$ & $\begin{array}{c}\text { Rhyan et al. } \\
\text { (2009) }\end{array}$ \\
\hline
\end{tabular}




\section{MATERIAL E MÉTODOS}

Foram coletadas 44 amostras de sangue de Ozotoceros bezoarticus das Fazendas Nhumirim (Campo experimental da Embrapa Pantanal), Porto Alegre, Dom Valdir e Alegria, localizadas na região central do Pantanal brasileiro, conhecida como Subregião Nhecolândia (18 59' 15' Sul, $56^{\circ} 37^{\prime}$ 03"' Oeste).

A captura dos veados campeiros foi realizada por meio de dardo anestésico, lançados a distância através de pistolas de CO2 com pressão regulável (modelo 35, Distinject $囚$, Basel, Suíça) ou uma zarabatana de $2 \mathrm{~m} \times 11 \mathrm{~mm}$ de diâmetro (Zootech®, Curitiba/PR, Brasil). A contenção química foi feita através da associação dos anestésicos Tiletamina e Zolazepam (Zoletil@ Virbrac, São Paulo/SP, Brasil), na dosagem de $10 \mathrm{mg} / \mathrm{kg}$ e também com associação de xilazina (Anasedan ${ }^{\circledR}$ Vetbrands, Paulínia/SP, Brasil) na proporção de 2:1 (3mg/ $\mathrm{kg}: 1 \mathrm{mg} / \mathrm{kg}$ ). Todos os procedimentos seguiram as recomendações do guia de captura, manuseio e cuidados com animais, aprovados pela sociedade de Mastozoólogos Americanos, com a autorização do Instituto Brasileiro do Meio Ambiente e de Recursos Naturais Renováveis (IBAMA), com as licenças ambientais de número (16010-1) 6425591/33454426, (003/ 2006) 0214.000540/2005-82, (005/2007) 02014.000382/200722, (015/2007) 02014.000 419/07-97, (003/2006) 0214.000540/ 2005-82.

O sangue coletado por meio de punção da jugular foi estocado no Banco de Coleção Biológicas da Embrapa Pantanal e enviado ao Laboratório de Biologia Molecular Animal da Embrapa Gado de Corte para as análises moleculares.

Realizou-se extração do DNA genômico a partir de 350ì de sangue total, utilizando $50 \mathrm{~mL}$ de proteinase $\mathrm{K}(20 \mathrm{mg} /$ $\mathrm{mL}$ ); $500 \mathrm{~mL}$ de (Dodecil Sulfato de Sódio) - SDS 10\%; $800 \mathrm{~mL}$ de clorofórmio e $400 \mathrm{~mL}$ da solução de precipitação protéica (3M C $\mathrm{M}_{3} \mathrm{KO}_{2}, 2 \mathrm{M} \mathrm{CH}_{3} \mathrm{COOH}$ ). A amostra foi centrifugada por $14000 \mathrm{xg} / 10 \mathrm{~min}$, o sobrenadante coletado e tratado com $1 \mathrm{~mL}$ de etanol absoluto, homogeneizou-se e centrifugou-se a $14000 x g / 5 \mathrm{~min}$. Descartou-se o sobrenadante e adicionouse $1 \mathrm{~mL}$ de etanol $70 \%$ ao sedimento formado. Logo após, a amostra foi centrifugada por $14000 \mathrm{xg} / 3 \mathrm{~min}$ e o sobrenadante descartado. O sedimento foi seco em temperatura ambiente e ressuspendido em $50 \mu \mathrm{L}$ de tris-EDTA (10mM Tris $\mathrm{HCl} \mathrm{pH} \mathrm{7,4,} 1 \mathrm{mM}$ EDTA pH 8.0) e estocado a $-20^{\circ} \mathrm{C}$.

Para a amplificação do gene virB5 de Brucella abortus pela técnica de PCR foram utilizados oligonucleotídeos iniciadores, citados em Hartigh et al. (2004), para uma região conservada do gene, que amplifica um produto de aproximadamente 550 pares de bases (pb) correspondente a posição 5063 a 5549 no genoma de B. abortus, no de acesso AF226278, no GenBank (http://www.ncbi.nlm.nih.gov). A amplificação foi realizada em termociclador com o seguinte protocolo: 35 ciclos de $95^{\circ} \mathrm{C} / 1 \mathrm{~min}, 60^{\circ} \mathrm{C} / 1 \mathrm{~min}, 72^{\circ} \mathrm{C} / 2 \mathrm{~min}$ e um ciclo final de $72^{\circ} \mathrm{C} / 3 \mathrm{~min}$. As reações de $\mathrm{PCR}$ foram realizadas em termociclador com gradiente (Eppendorf Mastercycler gradient), com um volume final de $50 \mu \mathrm{L}$ contendo $5 \mu \mathrm{L}$ de tampão de PCR 10X, 1,5mM de $\mathrm{MgCl}_{2}, 250 \mu \mathrm{M}$ de cada dNTP, 1,5 U de Taq DNA polimerase (VRJ) 5 pmoles de cada oligonucleotídeo iniciador e $1 \mu \mathrm{L}$ de DNA molde. Os produtos da amplificação foram submetidos à eletroforese a 100V por 1 hora em gel de agarose a $1 \%$, o qual foi corado com brometo de etídio e visualizado com transluminador sob luz ultravioleta. Como controle positivo da reação de PCR foi utilizado DNA genômico de B. abortus S2308.
Para as reações de seqüenciamento, foram escolhidas duas das nove amostras que apresentaram o fragmento de aproximadamente $550 \mathrm{pb}$. Estes fragmentos foram recortados do gel de agarose, purificados com Quiaex I/ gel extraction kit (Qiagen) e quantificados com padrão Low mass (Invitrogen).

A reação de seqüenciamento consistiu em $2 \mu \mathrm{L}$ de BigDye 3 (Applied Byosystems ${ }^{\mathrm{TM}}$ ), $2 \mu \mathrm{L}$ de tampão Save Money 5', 2pmol do oligonucleotídeos iniciadores montante e $8 \mathrm{ng}$ do produto de PCR purificado, para uma reação de $10 \mu \mathrm{L}$. A amplificação foi realizada em termociclador de gradiente (Eppendorf Mastercycler gradient), com desnaturação prévia de $94^{\circ} \mathrm{C} / 2 \mathrm{~min}$ e 25 ciclos de $96^{\circ} \mathrm{C} / 20 \mathrm{~s}, 60^{\circ} \mathrm{C} / 15$ s e $60^{\circ} \mathrm{C} /$ $4 \mathrm{~min}$. Estas reações também foram realizadas com os oligonucleotídeos iniciadores jusante. A seguir o produto desta reação foi tratado com $40 \mu \mathrm{L}$ de isopropanol a $75 \%$ por $15 \mathrm{~min}$, centrifugado a $14000 \mathrm{xg} / 25 \mathrm{~min}$ e o sobrenadante descartado. Posteriormente, foi adicionado $200 \mu \mathrm{L}$ de etanol a $60 \%$, centrifugou-se a $14000 \mathrm{xg} / 5 \mathrm{~min}$. O sedimento foi diluído com formamida e desnaturado a $95^{\circ} \mathrm{C} / 5 \mathrm{~min}$ e depois incubado a $4^{\circ} \mathrm{C} / 3 \mathrm{~min}$. Finalmente, as amostras foram seqüenciadas no seqüenciador automático $\mathrm{ABI} 3100$ (Applied Biosystems ${ }^{\mathrm{TM}}$ ), análises gentilmente realizadas pelo laboratório de Biotecnologia Animal da Embrapa Pecuária Sudeste.

As seqüências obtidas foram analisadas pelos programas PHRED, PHRAP e BioEdit 5.0.9. (Hall 1999), para avaliar a qualidade das seqüências e realizar o consenso e alinhamento das mesmas. Os resultados das seqüências analisadas foram realizadas pelo programa BLASTn (Basic Local Alignment Search Tool - NCBI), que procurou as seqüências homólogas no GenBank.

O gene virB5 de $B$. abortus isolado de veado campeiro e da cepa $\mathrm{S2803}$, cuja seqüência de nucleotídeos foi determinada neste estudo, foram alinhadas às seqüências desse mesmo gene de outras espécies de Brucella e a uma seqüência de Agrobacterim tumefaciens (acesso NC002377), que foi utilizado como grupo externo. O alinhamento foi inicialmente realizado com o auxílio do programa CLUSTAL W e posteriormente corrigido à mão com o auxílio do programa BioEdit 5.0.9. O tamanho das seqüências utilizadas na análise filogenética variou entre 408 a $436 \mathrm{pb}$, perfazendo um total de dois sítios variáveis em 436 posições alinhadas utilizando apenas os membros do gênero Brucella.

A árvore filogenética foi construída pelo método de Evolução Mínima (EM) implementado no programa MEGA 4.1 (Tamura et al. 2007), com 1.000 replicações de Bootstrap.

\section{RESULTADOS}

Das 44 amostras processadas, nove (20,4\%) apresentaram um fragmento de aproximadamente 550pb.

A seqüência consenso obtida no sequenciamento dos isolados de cervídeo apresentou 514pb e 95\% de identidade com virB5 de Brucella abortus (best hits acesso nr AF226278, e-value 0,0$)$; a seqüência consenso do controle positivo $B$. abortus 2308 apresentou 503pb e 97\% de identidade com virB5 de B. abortus (acesso nr AF226278, e-value 0,0) (Fig.1).

A árvore de EM construída com oito seqüências de Brucella baseada no gene virB5 está representada na Figura 2. Os valores representados nos nós internos da árvore correspondem à freqüência de replicação que recuperaram cada um deles nas 1.000 replicações geradas durante a análise de Bootstrap. 
CLUSTiL 2.0.10 multiple sequence 21 igroment

Bxace212 32308

$\operatorname{sinectin}=\mathrm{p}$.

B. zbortus AF226278

Baseces22 32308

$B \operatorname{xic}=2 \pi \Omega=\mathrm{P}$.

B. aboztus AF226278

Basect2a 2308

Bzectin $=\mathrm{p}$.

B. zboztus AF226278

Bzuce212 32308

Bxucel 2A sp.

B. zbortus AF226278

Buec212 32308

sasec23a $=\mathrm{P}$.

B. zbortus AF226278

sarect2a 32308

$B$ axe el2 $2 \mathrm{P}$.

s. 2bortus \&F226278

Bzace212 32308

Bxicedin sp.

B. aboztus \&F226278

Bzucel22 32308

$B \operatorname{sice} 2 \pi=\mathrm{P}$.

B. abontus AF226278

saces22 32308

Basedzas $=\mathrm{p}$.

B. abontus AF226278
--1--T TTG A

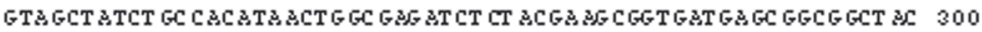

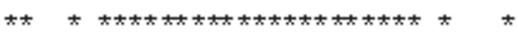

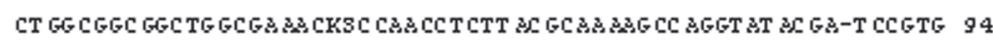

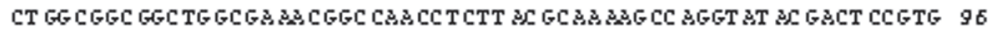

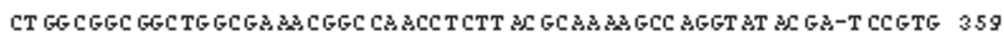

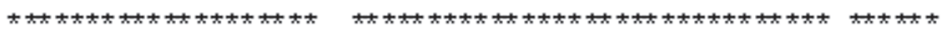

T GCCTCCATCT CC GACA A GATC-AGCGCATC GC AT GT GAGGCT AABGT-GGT GA גGC CG 152

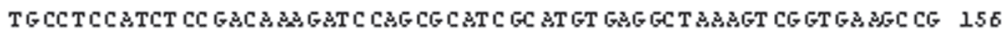

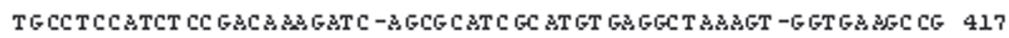

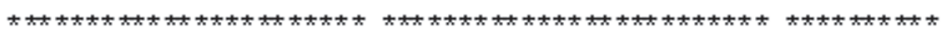

GT CC AGGACA GGT AT GA CGT CA3 GT CC AGGACA GGTCAT GACGTC CA GT CC AGGACABGGTCAT GACGTCCA A

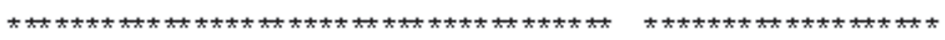

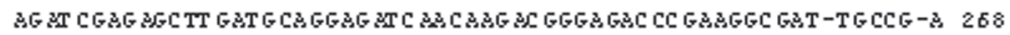
AG AT CGAG ASCTT GATGCAKGAG MTC AMCABG BSGGAGACCC GAAGGC GATGT GCCGTA 276

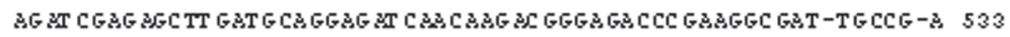
シ

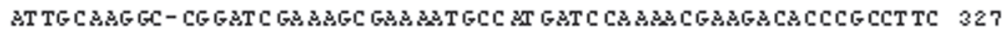

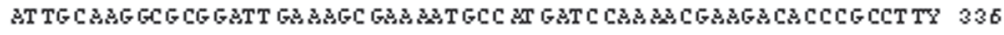

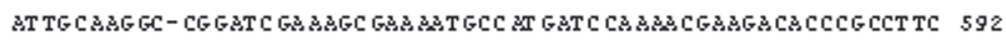

\#

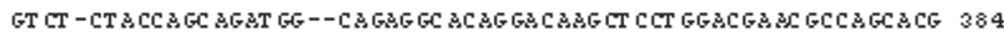

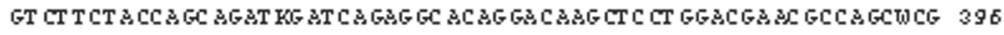

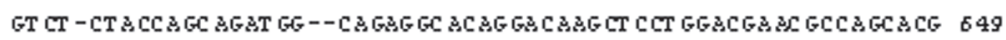

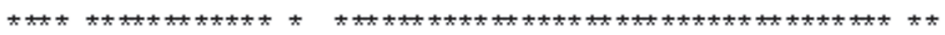

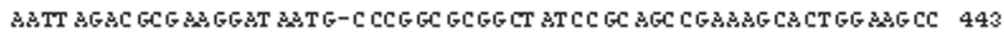

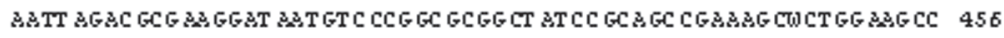

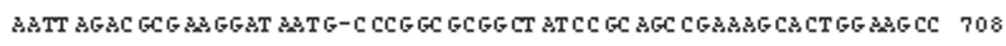

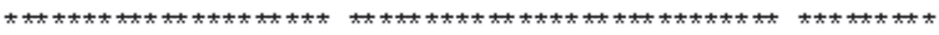

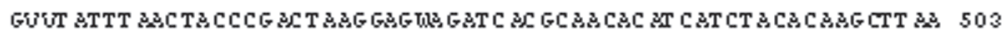

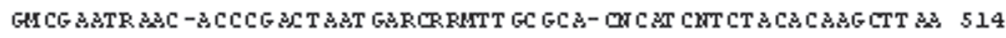

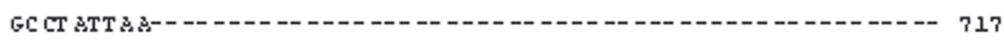

Fig.1. Alinhamento múltiplo de sequencias de virB 5 de Brucella abortus. Controle positivo ( $B$. abortus S 2308), Brucella sp. (isolado de Ozotoceros bezoarticus) e Brucella abortus (AF226278).

Pesq. Vet. Bras. 30(6):503-509, junho 2010 


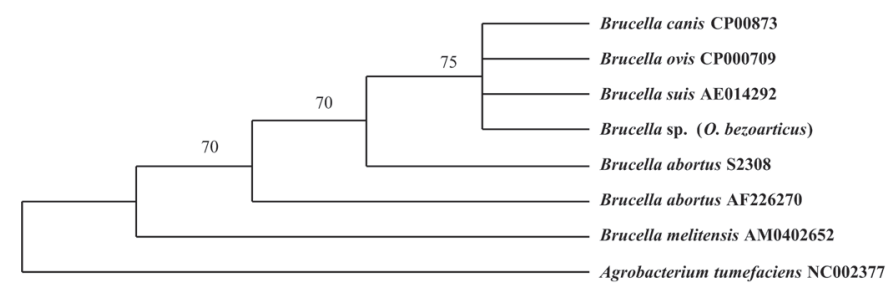

Fig.2. Filogenia de Brucella spp. utilizando-se o gene virB 5, pelo método de ME. Bootstrap.

A Figura 2 mostra que, após a separação de Agrobacterim tumefaciens, as demais bactérias Gram-negativas dividem-se em dois grupos. A primeira divisão basal forma um grupo definido, e reúne todas as espécies de Brucella e no outro grupo temos $B$. melitensis, logo após esta subdivisão temos uma nova divisão (aparece $70 \%$ das topologias geradas pela análise Bootstrap) em um ramo $B$. abortus (acesso AF226270) e no outro as outras espécies. Depois desta subdivisão, ocorre uma segunda segmentação (Bootstrap $=70 \%$ ) que deixa para um lado, B. abortus S2308 (seqüência obtida neste trabalho) e para outro lado as espécies de Brucella. Finalmente, a última grande subdivisão (Bootstrap $=75 \%$ ) contendo as espécies de $B$. canis, $B$. ovis, $B$. suis e o isolado de veado campeiro (sequência obtida neste trabalho).

\section{DISCUSSÃO}

Poucas informações têm sido estudas e reportadas sobre as doenças infecciosas que acometem cervídeos (Uhart et al. 2003). No trabalho realizado com cervídeos do Pantanal MatoGrossense-Sul por Mathias et al. 1999, todas as amostras de soros foram negativas no teste sorológico para $B$. abortus. Desta forma, estes autores consideraram que a brucelose não representaria um problema entre os cervídeos nas áreas estudadas e que estes animais não implicariam riscos para outros animais domésticos e silvestres, mesmo ponderandose que a brucelose bovina é comum em algumas áreas no Brasil, e que o estudo foi conduzido em animais silvestres de áreas co-habitadas por bovinos.

Entretanto, no presente estudo, utilizando-se número amostral maior e uma técnica mais sensível, a PCR, foi possível verificar uma prevalência amostral de 20,4\%; sugerindo que a brucelose pode ser um problema entre os veados campeiros na área estudada e que estes animais podem representam riscos para outros animais domésticos e silvestres.

Para o diagnóstico da maioria das doenças infecciosas, o fator mais importante é o isolamento por meio do cultivo, com posterior identificação do patógeno. Assim, é possível dizer que uma enfermidade infecciosa é diagnosticada com segurança depois do isolamento e identificação do agente. Porém, no caso da brucelose, este processo é lento e oneroso, principalmente pela necessidade de investigar muitos animais nos programas de vigilância, e de elevado risco por se tratar de importante zoonose (Molnár et al. 1997).

A PCR é uma técnica molecular, cuja escolha do DNA alvo e definição dos primers dentro da seqüência do DNA são fatores determinantes na sua acuidade. Esta técnica vem sendo utilizada como alternativa para o diagnóstico rápido de doenças infecciosas. Pelo 'Manual Técnico do PNCEBT' (Brasil 2006), a PCR permite a identificação de Brucella spp. em material de aborto e nas secreções de bovinos após o parto ou aborto, sendo uma prova de diagnóstico direto considerada de grande confiabilidade devido a sua alta especificidade e sensibilidade.

A árvore filogenética construída, pelo método de EM baseia-se nas distâncias entre as seqüências, sobre a substituição de nucleotídeos. Um dos fatos que mais chama atenção na árvore, mostrada na Figura 2, é a monofila das espécies $B$. canis, $B$. ovis e B. suis e Brucella sp. (isolada do veado campeiro). Vale ressaltar também a proximidade de Brucella sp. isolada de veado campeiro com B. suis (suíno).

Duas hipóteses alternativas podem ser invocadas para explicar a árvore filogenética construída com o gene virB5: 1) A primeira hipótese seria que as espécies de Brucella constituem uma única espécie; corroborando com a filogenia para outros genes (Verger et al. 1985, Moreno et al. 1990). Entretanto, esta visão é conflitante com a hipótese clássica evolutiva que denomina as espécies de acordo com os hospedeiros preferenciais e a comum associação entre patógenos-hospedeiros possibilita a classificação das espécies, e 2) A segunda hipótese estaria relacionada com co-habitação de porcos ferais com cervídeos levando em consideração a abundância destes animais na região do Pantanal (Alho \& Lacher 1991, Piovezan \& Avellar 2008) e que, em recente trabalho, a brucelose foi diagnosticada em $5 \%$ (8/162) de porcos ferais (Sus scrofa) investigados na mesma região (Paes et al. 2008). Um teste para confirmar a segunda hipótese é a construção de uma árvore filogenética da amostra isolada de veado campeiro utilizando outros genes que permitam a mensuração do sinal filogenético.

Forbes \& Tessaro (1993) confirmaram que renas (Rangifer tarandus) podem transmitir $B$. suis biovar 4 para bovinos, entretanto estes autores concluíram que os animais silvestres apresentam pouca significância na transmissão de Brucella spp. para bovinos nos Estados Unidos da América (EUA). Por outro lado, alguns autores consideram a brucelose um problema significativo em alces (Cervus elhapus) e em bisão (Bison bison) no Park Nacional Yellowstone (Ryan et al. 1997, Etter \& Drew 2006, Conner et al. 2008, Maichak et al. 2009, Olsen \& Tatum 2010, Olsen 2010). Diagnósticos sorológicos de Brucella spp. em alces tem revelado baixa prevalência de soros reativos, isto pode ser devido a severidade da doença que acaba sendo fatal, ou uma inerente resistência a doença e ou uma baixa a exposição à doença (Honour 1993, Maichak et al. 2009). Porém, em infecções experimentais foi possível verificar que a brucelose foi fatal em alces (Honour 1993). 
A gentipagem da região de 10 números variáveis de repetições em tandem (VNTR) no locus 56 do DNA de $B$. abortus isoladas de bisão, alces e bovinos (Bos taurus) para verificar as espécies mais provável responsável por surtos recentes de brucelose em bovinos na grande área de Yellowstone; sugeriu que os alces foram as espécies reservatórios da origem deste surto (Beja-Pereira, 2009).

Estudos recentes, propõem que a brucelose em animais silvestres podem ter sido adquirida no passado de animais domésticos, o que permitiu a persistência do agente causador desta doença (Olsen, 2005). Especialistas acreditam que a brucelose dos reservatórios silvestres é originada de bovinos. Numerosos estudos têm documentado que a brucelose em animais silvestres não é manifestada e nem transmitida e que estes animais seriam os hospedeiros finais (dead-and, bêco-sem-saída). Porém, problemas recorrentes são reportados, nos EUA nestes animais nos quais a doença é manifestada e a transmissão pode ocorrer (hospedeiros remanescentes) (Olsen \& Tatum 2010).

Estudos de inquéritos epidemiológicos para a identificação de fatores que afetam a saúde das populações de cervídeos são essenciais para o desenvolvimento de estratégias como, por exemplo, criação em cativeiro, programas de reintrodução, repopulação e harmonização entre animais domésticos e silvestres.

Agradecimentos.- À Fundação de Apoio ao Desenvolvimento do Ensino, Ciência e Tecnologia do Estado de Mato Grosso do Sul (Fundect) pelo apoio financeiro. À Dra. Luciana Regitano, Embrapa Pecuária Sudeste, pelo sequenciamento das amostras. À Dra Renata Cunha Madureira e a mestranda Renata Bastos pela ajuda na execução do trabalho.

\section{REFERÊNCIAS}

Aguirre A.A., McLean R.G., Cook R.S. \& Quan T.J. 1992. serologic survey for selected arboviruses and other potential pathogens in wildlife from Mexico. J. Wildl. Dis. 28:435-442.

Alho C.J.R. \& Lacher T.E. 1991. Mammalian conservation in the Pantanal of Brazil, p.280-294. In: Mares M. \& Schimidly D.J. (Eds), Latin American Mammalogy, History, Biology and Conservation. University of Oklahoma Press, Norman.

Beja-Pereira A., Bricke B.R., Chen S., Almendra C., White P.J. \& Luikart G. 2009. DNA genotyping suggests that recent brucellosis outbreaks in the Greater Yellowstone area originated from elk. J. Wildl. Dis. 45:1174-1177.

Brasil 2006. Programa Nacional de Controle e Erradicação da Brucelose e da Tuberculose Animal (PNCEBT), Ministério da Agricultura, Pecuária e Abastecimento. Organizadores: Figueiredo V.C.F., Lôbo J.R. \& Gonçalves V.S.P. MAPA/SDA/DSA, Brasília. 188p.

Boeer W.J., Crawford R.P., Hidalgo R.J. \& Robinson R.M. 1980. Small mammals and white-tailed deer as possible reservoir hosts of Brucella abortus in Texas. J. Wildl. Dis. 16:19-24.

Bourque M. \& Higgins R. 1984. Serologic studies on brucellosis, leptospirosis and tularemia in moose (Alces alces) in Quebec. J. Wildl. Dis. 20:95-99.

Cabrera A. 1943. Sobre la sistemática del venado y su variación individual y geográfica. Revta Museo de La Plata, Sección Zoológica, 3:5-41.

Conner M.M., Ebinger M.R., Blanchong J.A. \& Cross C.P. 2008. Infectious Disease in cervids of North America: Data, models and management challenges. N. Y. Acad. Sci. 1143:146-172.

Daguerre J.B. 1970. El venado o ciervo de las Pampas. Diana 363:2024.
Davidson W.R., Crum J.M., Blue J.L., Sharp D.W. \& Phillips J.H. 1985. Parasites, diseases, and health status of sympatric populations of fallow deer and white-tailed deer in Kentucky. J. Wildl. Dis.21:153-159.

Deem S.L., Noss A.J., Villarroel R., Uhart M.M. \& Karesh W.B. 2004 Disease survey of free-ranging grey brocket deer (Mazama gouazoubira) in the Gran Chaco, Bolívia. J. Wildl. Dis. 40:92-98

Drew M.L., Jessup D.A., Burr A.A. \& Franti C.E. 1992. Serologic survey for brucellosis in feral swine, wild ruminants, and black bear of California, 1977 to 1989. J. Wildl. Dis. 28:355-363

Etter R.P. \& Drew M. 2006. Brucellosis in elk of eastern Idaho. J. Wildl. Dis. 42:271-278.

Forbes L.B. \& Tessaro S.V. 1993. Transmission of brucellosis from reindeer to cattle. J. Am. Vet. Med. Assoc. 203:289-294.

García Fernández J.J., Ojeda R.A., Fraga R.M., Díaz G.B. \& Baigún R.J. 1996. Libro rojo de mamíferos y aves amenazados de la Argentina. Ed. Fucema y Administración de Parques Nacionales, Buenos Aires. 221p.

Gonzáles S., Cosse M., Braga F.G., Vila A.R., Merino M.L., Dellafiore C., Cartes J.L., Maffei L. \& Dixon M.G. 2010. Pampamas deer Ozotoceros bezoarticus (Linnaeus, 1758), p.119-132. In: Duarte J.M.B. \& Gonzáles S. (Eds), Neotropical Cervidology: Biology and medicine of neotropical deer. Funep and IUCN, Jaboticabal.

Hall T.A. 1999. BioEdit: A user-friendly biological sequence alignment editor and analysis program for windows 95/98/NT. Nucleic Acids Symposium 41:95-98.

Hartigh A.B., Sun Yao-Hui, Sondervan D., Heuvelmans N., Reinders M.O., Ficht T.A. \& Tsolis R.M. 2004 Differential for VirB1 and VirB2 during Brucella abortus infection. Infect. Immun. 72: 5143-5149.

Holloway C. 1975. Threatened deer of the world: Research and conservation projects under the IUCN Programme. Deer 3:428-433.

Honour S. \& Hickling K.M.H. 1993. Naturally occurring Brucella suis Biovar 4 Infection in a moose (Alces alces). J. Wildl. Dis. 29:596-598

Ingebrigtsen D.K., Ludwig J.R. \& McClurkin A.W. 1986. Occurrence of antibodies to the etiologic agents of infectious bovine rhinotracheitis, parainfluenza 3 , leptospirosis, and brucellosis in white-tailed deer in Minnesota. J. Wildl. Dis. 22:83-86

Jackson J. \& Lanagutth A. 1987. Ecology and status of pampas deer (Ozotoceros bezoarticus) in the Argentinean pampas and Uruguay, p.402-409 In: Wemmer C.M. (Ed.), Biology and Management of the Cervidae. Smithsonian Institution Press, Washington, DC.

Jones R.L., Tamayo R.I., Porath W., Giessman N., Selby L.S. \& Buening G.M. 1983. A serologic survey of brucellosis in white-tailed deer (Odocoileus virginianus) in Missouri. J. Wildl. Dis. 19:321-323.

Lord V.R. \& Flores R. 1983. Brucella spp. from the capybara (Hydrochaeris hydrochaeris) in Venezuela: Serologic studies and metabolic characterization of isolates. J. Wildl. Dis. 19:308-314.

Mathias L., Girio R.J.S. \& Duarte J.M.B. 1999. Serosurvey for antibodies against Brucella abortus and Leptospira interrogans in pampas deer from Brazil. J. Wildl. Dis. 35:112-114.

Maichak E.J., Scurlock B.M., Rogerson J.D., Meadows L.L., Barbknecht A.E., Edwards W.H. \& Cross P.C. 2009. Effects of management, behavior, and scavenging on risk of brucellosis transmission in elk of Western Wyoming. J. Wildl. Dis. 45:398-410

Merrell C.L. \& Wright D.N. 1978. Serologic survey of mule deer and elk in Utah. J. Wildl. Dis. 14:471-478.

Molnár L., Molnár É., Túry E. \& Sousa J.S. 1997. Concepções modernas para o diagnóstico da brucelose. Revta Bras. Med. Vet. 19:157-162.

Moreno E., Stackebrandt E., Dorsch M. \& Wolters J. 1990. Brucella abortus 16S rRNA and lipid A reveal a phylogenetic relationship with members of the alpha-2 subdivision of the class Proteobacteria. J. Bacteriol. 172:3569-3576.

Mourão G., Coutinho M., Mauro R., Campos Z., Tomás W. \& Magnusson W. 2000. Aerial Surveys of caiman, marsh deer and pampas deer in the Pantanal Wetland of Brazil. Biol. Conservation 92:175-183. 
Nascimento A.A., Bonuti M.R., Mapeli E.B., Tebaldi J.H., Arantes I.G. \& Zettermann C.D. 2000. Infecções naturais em cervídeos (Mammalia: Cervidae) procedentes dos Estados do Mato Grosso do Sul e São Paulo, por nematódeos Trichostrongyloidea Cram, 1927. Braz. J. Vet. Res. Anim. Sci. 37: online ISSN 1413-9596. doi: 10.1590/S141395962000000200012.

Olsen S. \& Stoffregen W.S. 2005. Essential role of vaccines in brucellosis control and eradication programs for livestock. Expert Rev. Vaccines 4:915-928.

Olsen S. \& Tatum F. 2010. Bovine Brucellosis. Vet. Clin. Food Anim. 26:18-27.

Olsen S. 2010. Brucellosis in the United States: Role and significance of wildlife reservoirs. Vaccine. doi:10.1016/j.vaccine.2010.03.059.

Paes R.C.S., Ribeiro O.C., Carneiro Monteiro L.A.R., Figueiredo A.O., Neto A.A.C., Oliveira J.M., Da Rosa G.O., Keuroglian A., Piovezan U. \& Herrera H.M. 2008. Enfermidades de ocorrência no porco monteiro (Sus scrofa) no Pantanal Sul-Mato-Grossense, Brasil. Anais 35 Conbravet, Gramado, RS, p.47. (Resumo)

Piovezan U. \& Avellar A.L.F. 2008. Quantos porcos monteiros existem no Pantanal. Circular Técnica 76, Embrapa Pantanal, Corumbá. 4p. Disponível em <http://www.cpap.embrapa.br/publicacoes/ download.php?arq_pdf=CT76>. Acesso em 30 ago. 2008.

Poester F.P., Gonçalves V.S.P. \& Lage A.P. 2002. Brucellosis in Brazil. Vet. Microbiol. 90:55-62.

Rhyan J.C., Aune K., Ewalt D., Marquardt J., Mertins J.W., Payeur J.B., Saari D.A., Schladweiler P., Sheehan E.J. \& Worley D. 1997. Survey of free-ranging elk from Wyoming and Montana for selected pathogens. J. Wildl. Dis. 33:290-298.
Rhyan J.C., Aune K., Thomas R., Ewalt D., Hennager S., Gidlewski T., Olsen S. \& Clarke R. 2009. Pathogenesis and epidemiology of brucellosis in Yellowstone bison: Serologic and culture results from adult females and their progeny. J. Wildl. Dis. 45:729-739

Tamura K., Dudley J., Nei M. \& Kumar S. 2007. MEGA 4: Molecular Evolutionary Genetics Analysis (MEGA) software version 4.0. Mol. Biol. Evol. 24:1596-1599.

Tomás W.M., McShea W., Miranda G.H.B., De Moreira J.R., Mourão G.E. \& Lima Borges P.A. 2001. A survey of pampas deer, Ozotoceros benzoarticus leucogaster (Artiodactyla, Cervidae), population in the Pantanal wetland, Brazil using the distance sampling technique. Anim. Biol. Conserv. 24 (1):101-106.

Thornback J. \& Jenkins M. 1982. The IUCN Mammal Red Data Book. Part II. International Union for the Conservation of Nature. Switzerland, p.516.

Thorne E.T., Smith S.G., Aune K., Hunter D. \& Roffe T.J. 1997. Brucellosis: The disease in elk, p.33-44. In: Thorne E.T., Boyce M.S., Nicoletti P. \& Kreeger T.J. (Eds), Brucellosis in bison, elk and cattle in the Greater Yellowstone area: Defining the problem, exploring the solutions. Wyoming Game and Fish Department, Cheyenne, Wyoming.

Uhart M.M., Vila A.R., Beade M.S., Balcarce A. \& Karesh L.B. 2003. Health evaluation of pampas deer (Ozotoceros bezoarticus celer) at Campos del Tuyú Wildlife Reserve, Argentina. J. Wildl. Dis. 39:887-893.

Verger J., Grimont F., Grimont P.A.D. \& Grayon M. 1985. Brucella a monospecific genus as shown by deoxyribonucleic acid hybridization. Int. J. Syst. Bacteriol. 35:292-295.

Viglizzo E. 1994. Condición y tendencia de los recursos naturales y la sustentabilidad en Argentina, p.89-91 In: Puignan J.P. \& Buschinelli C.C.A. (Eds), IICA-Procisur, Montevideo, Uruguay. 